\title{
Peak Pressure Rise Rate
}

National Cancer Institute

\section{Source}

National Cancer Institute. Peak Pressure Rise Rate. NCI Thesaurus. Code C139044.

The greatest rate of increase in peak pressure during muscle contraction. 